\title{
Self-Assessed Gap of Acquired and Desired Assessment Skills of Prospective Teachers
}

\author{
Muhammad Sarwar* \\ Muhammad Perveiz ${ }^{* *}$ \\ Mubashar Nadeem ${ }^{* * *}$
}

\begin{abstract}
The difference between the skills desired to carry out as sessments tasks and $t$ he $s$ kills a ctually a cquired du ring $p$ re-service $t$ eaching $t$ raining program by pros pective teachers is being referred to as skills' $g$ ap. The study dr aws $\mathrm{i}$ ts ba sis from $5^{\text {th }}$ national professional $\mathrm{s}$ tandards $\mathrm{f}$ or teachers, which describes necessary assessment skills for teachers. This study intends to find out the a ssessment sk ills of p rospective teachers. The as sessment skills consisting of 39 items and three subscales were used to collect da ta from $333 \mathrm{pr}$ ospective t eachers s elected from four public sector universities of central $\mathrm{P}$ unjab. The majority of the prospective $t$ eachers a cquired a m oderate 1 evel o f asse ssment sk ills (Mean=4.37, $\mathrm{SD}=0.96)$. The average desired level of assessment skills (Mean $=5.45, \mathrm{SD}=0.91$ ) was higher than the acquired level majority of the prospective teachers ac quired a moderate level of asses sment skills. Positive relationship between acquired and desired level of asses sment skills leads to the conclusion that the prospective teachers $w$ ho desire higher level of a ssessment skills achieve comparatively higher level and vice versa. Gender differences were found in existing and desired selfassessed as sessment sk ills, knowledge of assessment, di spositions towards ass essment and skills of a ssessment in the favour of $f$ emale' prospective teachers. The study may contribute to improve the achieved level of a ssessment sk ills by sens itizing the p rospective teachers a nd teacher educ ators about the si gnificance of desired level of assessment skills in improving the acquired level.
\end{abstract}

* Associate Professor, University of Sargodha. Email: drsarwar@ymail.com

** PhD Scholar, University of Sargodha, Sargodha.

*** Assistant Professor, University of Education, Lahore. 


\section{Introduction}

Teacher Education is a key to improve the quality of teaching force. Quality teacher education requires standards which result in teachers' competences as 1 earning outcomes of standard based teacher education. Assessment is one of these na tional pro fessional standards for teacher education in Pakistan. Assessment sk ills ar e 1 earning out comes of assessment $\mathrm{s}$ tandard of $\mathrm{t}$ eacher e ducation. $\mathrm{T}$ he pr esent $\mathrm{s}$ tudy is a bout achievement 1 evel of a ssessment sk ills o f pro spective $t$ eachers $w$ ho recently completed their pre-service teacher training in four universities of central Pakistan.

Assessment sk ills ar e i mportant com ponents of t he $t$ eacher's effectiveness (Darling-Hammond \& B erry, 2006; Khan \& Saeed, 2009; Korthagen, 2004). The evaluation of classroom activities and disposition of $t$ eachers towards remarkable $t$ eaching can be e ffective by us ing different ass essment skills (Shavelson et al., 2008; Waugh \& Gronlund, 2013). The performance of teachers in this procedure is linked to setting of knowledge, dispositions and skills of assessment.

Classroom assessment aims at improving students' 1 earning and motivation. It ha $\mathrm{s}$ be come a $\mathrm{t}$ ool $\mathrm{f}$ or $\mathrm{i}$ mproving $\mathrm{l}$ earning outcomes of students. S pecific criteria of as sessing successful performance, timely and detailed $f$ eedback t $\mathrm{o} s$ tudents ar e the ess ential $r$ equirements of an act ive assessment. Teachers are required to develop ass essment skills that give a clear $\mathrm{u}$ nderstanding $\mathrm{t}$ ot he $\mathrm{s}$ tudents 1 earning an $\mathrm{d}$ assessment $\mathrm{p}$ rocess (Darling-Hammond \& B erry, 2006; Stiggins, 2002 ). T his s tudy may contribute to reduce the gap between existing and required assessment skills of prospective teachers by sensitizing the prospective teachers, teacher educators and other stake holders. The focus of the study is to explore gap between the existing and the desired level of assessment skills.

Hence, the proposed study intends to investigate the level of acquired assessment skills, which is the fifth standard of teacher Education.

\section{Methodology}

The study $\mathrm{w}$ as de scriptive in nature. A s urvey $\mathrm{w}$ as $\mathrm{c}$ onducted to determine a cquired and de sired assessment sk ills level of $t$ he respondents. P earson correlation was u sed to de termine na ture a nd direction of $r$ elationships be tween acquired a nd de sired level o $f$ assessment skills. Thus the study followed quantitative approach. 


\section{Respondents}

The $\mathrm{r}$ espondents of the study w ere 333 ( $251 \mathrm{f}$ emale $82 \mathrm{~m}$ ale) prospective teachers, who were about to complete their Bachelor degree in E ducation. The $\mathrm{r}$ espondents $\mathrm{w}$ ere selected from four un iversities of central Punjab (Pakistan).

\section{Assessment of Assessment skills}

Self-assessment procedure was used to assess acquired and desired level of as sessment $\mathrm{s}$ kills of $\mathrm{p}$ rospective $\mathrm{t}$ eachers. $\mathrm{T}$ he al ternative as sessment procedures $\mathrm{w}$ ere $\mathrm{p}$ eer-assessment, an $\mathrm{d}$ au thentic as sessment. In $\mathrm{p}$ eer assessment fellows of the same rank ass ess while in authentic as sessmentassessment is made in real life si tuation where as sesses act ually use their assessment $\mathrm{s}$ kills. A $\mathrm{s} t$ he both $\mathrm{w}$ ere more $t$ ime $t$ aking; $t$ hese $\mathrm{w}$ ere $\mathrm{n}$ ot adopted due to constraints of time and resources. Many authors have opined in s upport of s elf-assessment of skills as an al ternative when o ther more authentic methods are not feasible (Shah, 2009).

\section{Instrument}

To evaluate the self-assessed existing and desired level of assessment skills of B E d graduates a qu estionnaire w as developed by the researchers on the basis of statements given in the document of "National Professional S tandards for T eachers in P akistan". This i nstrument w as developed on personality measures scales and bases on the perception of self-assessment which will be supportive for learners in self-awareness, development and growth. It will also be helpful for the narration of their developing $r$ equirements in a $r$ ight $\mathrm{w}$ ay; he nce, for $\mathrm{t}$ he ch ecking of existing and desired level of as sessment skills the instrument was us ed. There were two parts of the instrument: "acquired", and "desired".

In $\mathrm{t}$ he "acqu ired level" the B E d graduates $\mathrm{w}$ ere ask ed to rate themselves that how much they ha ve at tained the as sessment skills. In "desired level", the future teachers were asked to rate the desired level of assessment skills having an ideal teacher. A self-assessment seven point likert scale was used for the judgement of these levels. Consequently, the researchers developed a new questionnaire to collect the data from B Ed graduates. The $r$ esearchers $r$ eviewed the document of " $N$ ational Professional S tandards $\mathrm{f}$ or Teachers by $\mathrm{M}$ inistry of $\mathrm{E}$ ducation" completely. There are " ten professional standards for teachers in Pakistan". Keeping in view the requirements of the study, 39 items were 
developed and di vided the i nstrument in three $\mathrm{p}$ arts i .e. "knowledge, dispositions and skills", as $\mathrm{g}$ iven in the doc ument of " $\mathrm{N}$ ational Professional S tandards for T eachers". Each i ndicator of the instrument has two levels for rating i.e., acquired and required level. In knowledge level there were 13 items (e.g., My Current study programme enabled me to unde rstand the term 'criterion $r$ eference t est'). I n di spositions l evel there were 7 items (e.g., My Current study programme has developed the ability of doing fair as sessment) and in skills level 19 items (e.g., My Current study programme made me able to analyse student performance using multiple sources of data) were developed. Instrument level wise detail of items was as under:

Table 1

Instrument level wise detail of items

\begin{tabular}{lll}
\hline Sr. No & Indicators of assessment & No of items \\
\hline 1 & Knowledge & 13 (1 to 13) \\
2 & Dispositions & 7 (14 to 20) \\
3 & Skills & 19 (21 to 39) \\
\hline
\end{tabular}

In or der to check the validity of the instrument in terms of content and format, the instrument was discussed with experts of r elevant field. The instrument was improved in the light of their comments. Pilot study was conducted on a sample of 50 students, who were not included in the main study. The reliability estimates of acquired and desired levels of assessment skills w ere 0.920 and 0.972 (Cronbach Alpha) respectively which showed that the instrument was highly reliable.

\section{Analysis of the Data}

After data collection, the incomplete and improperly filled responses were discarded by the researchers. The data w ere analysed after data editing and correcting aberrant values followed by replacing of missing values. The de scriptive st atistics $\mathrm{W}$ as $\mathrm{u}$ sed to measure the level of existing and desired level of assessment skills of B Ed graduates. Paired sample $t$ test was used to determine the gap between existing and desired level of as sessment skills of B. Ed graduates. Pearson correlation w as calculated to find o ut the $\mathrm{r}$ elationship a cquired a nd de sired level of assessment skills of B. Ed graduates. 
Table 2

Acquired and Desired Assessment Skills Levels

\begin{tabular}{llll}
\hline Variables & Nature & Mean $(\mathrm{SD})$ & Interpretation \\
\hline \multirow{2}{*}{ Assessment Skills } & Desired & $5.45_{(0.91)}$ & High \\
& Acquired & $4.37_{(0.96)}$ & Medium \\
\multirow{2}{*}{ Knowledge } & Desired & $5.36_{(1.08)}$ & High \\
& Acquired & $4.40_{(0.98)}$ & Medium \\
\multirow{2}{*}{ Disposition } & Desired & $5.41_{(1.08)}$ & High \\
& Acquired & $4.49_{(1.07)}$ & Medium \\
\multirow{2}{*}{ Skills } & Desired & $5.49_{(0.94)}$ & High \\
& Acquired & $4.32_{(0.98)}$ & Medium \\
\hline $\mathrm{N}=333,1-3$ low, 3-5 Medium, 5-7 High & &
\end{tabular}

The table 1 shows the mean score of de sired and acquired level of assessment skills. The seven point scale having six intervals was divided into th ree equal parts: low (1-3), medium (3-5) and hi gh (5-7). The desired level of as sessment skills was high while the acquired level of assessment sk ill $\mathrm{w}$ as $\mathrm{m}$ edium of B E d graduates i n total assessment skills, knowledge of assessment, disposition towards assessment and use of assessment skills.

Table 3

Comparison Acquired and Desired Assessment Skills

\begin{tabular}{|c|c|c|c|c|c|c|}
\hline Variables & Nature & Mean (SD) & Gap & $D f$ & $\mathrm{~T}$ & $P$ \\
\hline $\begin{array}{l}\text { Assessment } \\
\text { Skills }\end{array}$ & $\begin{array}{l}\text { Desired } \\
\text { Acquired }\end{array}$ & $\begin{array}{l}5.45(0.91) \\
4.37(0.96)\end{array}$ & 1.08 & 332 & 24,16 & 0.000 \\
\hline Knowledge & $\begin{array}{l}\text { Desired } \\
\text { Acquired }\end{array}$ & $\begin{array}{l}5.36(1.08) \\
4.40(0.98)\end{array}$ & 0.96 & 332 & 19.55 & 0.000 \\
\hline Disposition & $\begin{array}{l}\text { Desired } \\
\text { Acquired }\end{array}$ & $\begin{array}{l}5.41_{(1.08)} \\
4.49_{(1.07)}\end{array}$ & 0.92 & 332 & 19.39 & 0.000 \\
\hline Skills & $\begin{array}{l}\text { Desired } \\
\text { Acquired }\end{array}$ & $\begin{array}{l}5.49_{(0.94)} \\
4.32_{(0.98)}\end{array}$ & 1.17 & 332 & 21.67 & 0.000 \\
\hline
\end{tabular}

The table 2 shows that the desired level of assessment skills was higher than the acquired level of as sessment skills. Similarly the desired level was higher in knowledge of assessment, dispositions towards assessment and use of as sessment s kills o fB.Ed graduates. T he maximum gap w as s hown between d esired an d acq uired u se of ass essment s kills an d minimum gap was found in dispositions towards assessment. 
Table: 4

Relationship between acquired and desired level of assessment skills

\begin{tabular}{|c|c|c|c|c|}
\hline Variable & $\begin{array}{l}\text { Acquired } \\
\text { assessment skills }\end{array}$ & $\begin{array}{l}\text { Acquired } \\
\text { Knowledge } \\
\text { Of assessment }\end{array}$ & $\begin{array}{l}\text { Acquired } \\
\text { Dispositions } \\
\text { towards } \\
\text { assessment }\end{array}$ & $\begin{array}{l}\text { Acquired Skills } \\
\text { in assessment }\end{array}$ \\
\hline $\begin{array}{l}\text { Desired } \\
\text { assessment } \\
\text { skills }\end{array}$ & $0.622^{* k}(p=0.000)$ & & & \\
\hline $\begin{array}{l}\text { Desired } \\
\text { Knowledge } \\
\text { Of assessment }\end{array}$ & & $0.623^{\star \star}(p=0.000)$ & & \\
\hline $\begin{array}{l}\text { Desired } \\
\text { Dispositions } \\
\text { towards } \\
\text { assessment }\end{array}$ & & & $0.549^{* *}(\mathrm{p}=0.000)$ & \\
\hline $\begin{array}{l}\text { Desired Skills } \\
\text { in assessment }\end{array}$ & & & & $0.622^{* k}(p=0.000)$ \\
\hline
\end{tabular}

Table 3 reflects that there was a significant positive correlation between desired level and acqui red level of a ssessment sk ills of B Ed graduates. S imilarly t he pos itive c orrelation $\mathrm{w}$ as $\mathrm{f}$ ound be tween $\mathrm{t}$ he desired and acquired level of $\mathrm{k}$ nowledge of as sessment, di spositions towards ass essment and use of sk ills in assessment of B .Ed graduates. The positive correlation leads that the graduates who had acquired high level wanted to get high level of as sessment skills. The graduates who had a cquired m edium level wanted to get medium l evel of asse ssment skills.

\section{Discussion}

The $\mathrm{m}$ ain pu rpose of $\mathrm{t}$ he $\mathrm{s}$ tudy $\mathrm{w}$ as $\mathrm{t}$ of ind ou $\mathrm{t} t$ he $\mathrm{g}$ ap be tween desired and a cquired level of $\mathrm{s}$ elf-perceived assessment sk ills o $\mathrm{f}$ prospective teachers. The desired skill level was high while the acquired skill level $\mathrm{w}$ as medium based on tripartite division of the scale ranging from 1 ow $\mathrm{t} o \mathrm{~h}$ igh a nd $\mathrm{c}$ onsideration o $\mathrm{ft}$ heir $\mathrm{c}$ orresponding $\mathrm{s}$ cores. Prospective $t$ eachers de sired hi gh 1 evel of $\mathrm{k}$ nowledge, di sposition a nd skills of assessment. While their acquired level of knowledge, disposition and skills of assessment was medium. Especially there was a large gap between desired and acquired level o $\mathrm{f}$ assessment skills and the prospective teachers were not satisfied to the acquired assessment skills.

The assessment skills were measured through self-assessment rating scale and some aut hors $t$ alk about $t$ hat $t$ he us ed criteria in the se lf- 
assessments tend to ignore the effectiveness of the overall organization of the institution (Pounder, 2000). Some authors also argued about overestimation of sk ills as sessed through self-report m ethod (Bratkovich, 2014; Falchikov \& Boud, 1989; Pinner, 2016 ). The probable reason of over estimation might be due to natural tendency of preferring own work to others'. Secondly, prospective teachers might not have perceived the level actually desired for them by their teachers and other stake holders. But interestingly the pr esent s tudy s hows that in s pite of the fact that despite ov erestimation the acquired assessment skill was not as per satisfaction of prospective teachers. So the actual gap may be more than presented in the study.

The gap might have be en due to teaching and a ssessment methods that ar e lecture and paper pe ncil respectively, in $\mathrm{P}$ akistan which promotes only knowledge level of learning. Unfortunately in Pakistan the skills are neither $t$ aught nor assessed in the $t$ eacher education area. Although $\mathrm{m}$ ost of the $\mathrm{f}$ aculty $\mathrm{m}$ embers a nd $\mathrm{s}$ tudents think $\mathrm{t}$ hat the assessment sy stem ne eds to be cha nged from knowledge emphasis to skill em phasis but i mplementation is ha mpered by t eacher edu cators lacking skills and hard work as w ell as un-acceptability on the part of senior $m$ anagement. From $t$ eachers' $s$ ide it $m$ ay b e due $t$ o $l$ ack of competence, expo sure and training of assessment skills. S o far a s the unacceptability from management side is concerned it may be due to lack of exposure of assessment skills, confidence, standardised practices and departmental/organizational politics.

Due to the a bove mentioned hu rdles the importance of asse ssment skills is not highlighted. Hence, the students are not able to understand the importance of these skills. The students who w ere se nsitised about the assessment skills desired high level of assessment skills. The findings of the study also indicate that the self-assessed acquired assessment skills had positive relationship with desired level of assessment skills.

The similar study on assessment skills was conducted in Oman (Alkharusi, Aldhafri, A lnabhani, \& Alkalbani, 2012). In this study four indicators of educational assessment (dispositions, competence, knowledge and practices) $w$ ere $t$ aken. The $r$ esults of $t$ he $s$ tudy $w$ ere similart ot his study. A nother s tudy w as a lso c onducted b y Ogan-Bekiroglu (2009) which c oncluded that teachers' k nowledge and conceits $r$ elated to the e ducational $v$ alue should be in a ccount $w$ hen showing a $\mathrm{n}$ educational policy i $\mathrm{ns}$ ystem. A s tudy, $\mathrm{c}$ onducted by (Stiggins, 2002), pointed out low as sessment 1 iteracy of ass essment, which was causing inaccurate assessments of students learning. 


\section{Conclusions}

1. It w as conc luded that the there is a $g$ ap between the se lf-assessed desired and acquired level of asses sment skills of B.Ed g raduates. The sel $\mathrm{f}$-assessed acquired 1 evel i s 1 ess than the de sired level of assessment skills of B .Ed graduates. The self-assessed desired level was high in the rating scale but the acquired level was medium in the scale.

2. It was al so concluded that there was a p ositive correlation between self-assessed desired and acquired level of assessment skills of B Ed graduates. It manifests that the students who wanted to get high level of s kills a cquired higher level than those who de sired low level of skills.

\section{Recommendations}

In the light of findings and results of the study the researchers put forward some recommendations:

1. The existing level of assessment skills is far below than the optimal level; he nce the qua lity of teaching s hould be i mproved. Skill learning $r$ equires pr actical act ivity, so it i $s \mathrm{r}$ ecommended that practical assessment of students, during teaching practice of prospective teachers, should be made part of teaching practice.

2. To increase the desired level of asses sment skills the prospective teachers need to be sen sitised regarding si gnificance of a ssessment skills in teaching through lectures and other appropriate techniques. The a wards $m$ ay be a nnounced on $t$ he ba sis of performance i $n$ assessment skills for the enc ouragement of $f$ uture na tion bu ilders having better assessment skills. The seminars and workshops should be arranged to highlight the importance of assessment skills. 


\section{References}

Alkharusi, H., Aldhafri, S., Alnabhani, H., \& Alkalbani, M. (2012). Educational assessment at titudes, co mpetence, $\mathrm{k}$ nowledge, a nd $\mathrm{p}$ ractices: An exploratory study of Muscat teachers in the Sultanate of Oman. Journal of Education and Learning, 1(2), 217.

Bratkovich, M . O . ( 2014). A ssessment a nd F eedback: E xamining t he Relationship B etween S elf-assessment a nd B lind P eer-and T eacherassessment i n T OEFL W riting. Working Papers in TESOL \& Applied Linguistics, 14(2), 100-127.

Darling-Hammond, L ., \& B erry, B . (2006). H ighly q ualified t eachers for al 1. Educational Leadership, 64(3), 1-7.

Falchikov, N., \& Boud, D. (1989). Student self-assessment in higher education: A meta-analysis. Review of Educational Research, 59(4), 395-430.

Khan, S . H ., \& S aeed, M . ( 2009). E ffectiveness o f Pre-service T eacher Education P rogramme ( B. E d) in P akistan: P erceptions of $\mathrm{G}$ raduates a nd their Supervisors'. Bulletin of Education and Research, 31(1), 83-98.

Korthagen, F. A. (2004). In search of the essence of a good teacher: Towards a more holistic ap proach i $\mathrm{n}$ teacher ed ucation. Teaching and Teacher Education, 20(1), 77-97.

Ogan-Bekiroglu, F. (2009). A ssessing Assessment: Examination of pre-service physics teachers' a ttitudes to wards a ssessment and factors a ffecting their attitudes. International journal of science education, 31(1), 1-39.

Pinner, R. (2016). Using s elf-assessment to maintain motivation in a dynamic classroom e nvironment: An Exploratory P ractice i nquiry of o ne J apanese university speaking course. The Asian Journal of Applied Linguistics, 3(1), $27-40$.

Pounder, J . S . ( 2000). A b ehaviourally an chored $r$ ating s cales ap proach t o institutional self-assessment in higher education. Assessment \& Evaluation in Higher Education, 25(2), 171-182.

Shah, A. A. (2009). Apports et limites de l'auto-évaluation des compétences par les diplômés de l'enseignement supérieur. Université de Bourgogne.

Shavelson, R. J., Y oung, D. B., A yala, C. C., B randon, P. R., F urtak, E. M ., Ruiz-Primo, M. A., ... Y in, Y . (2008). O $n$ the i mpact of c urriculum- 
embedded formative assessment on learning: A collaboration between curriculum and assessment developers. Applied Measurement in Education, 21(4), 295-314.

Stiggins, R. J. (2002). Assessment crisis: The absence of assessment for learning. Phi Delta Kappan, 83(10), 758-765.

Waugh, C. K., \& Gronlund, N. E. (2013). Assessment of student achievement. New Jersey: Pearson New Jersey.

Received on: August 20, 2016

Revised on: December 05 , 2016

Accepted on: December 28, 2016 